\title{
24. What Can the Murray-Darling Basin Plan Achieve? Will it be enough?
}

\author{
Neil Byron
}

The Murray-Darling Basin Authority (MDBA) has been criticised by many for what it has done so far, and how it has managed and communicated its extraordinary task. Debate is raging about whether the MDBA should reduce the amount of water irrigators are allowed to extract from rivers across the whole Murray-Darling Basin (MDB): not at all (as many irrigators assert); by 3000-4000 gigalitres (as the MDBA is currently considering); or by up to 7600 GL (as many environmental non-governmental organisations are demanding).

For comparison, according to the MDBA's recent Guide to the proposed Basin Plan (2010), under the current rules, the long-term average aggregate extraction plus interceptions is 13677 GL or 43 per cent of the estimated long-term natural flows. The long-term average environmental use is $13996 \mathrm{GL}$ or 44 per cent of the estimated long-term natural flows. The balance-a long-term average of 5105 GL or 15 per cent of the estimated long-term natural flows - reaches the Murray River mouth. As an example, one of the MDBA's scenarios-reducing the total extraction by 4000 GL below current levels - would make these percentages 30 per cent for irrigators, 48 per cent for the environment and 24 per cent for the river mouth.

The purpose of this chapter, however, is not to debate the 'right' level of reduction in average levels of water extraction by irrigators. The central argument is that successive Federal Governments' entire MDB 'strategies' have not been well designed or well implemented. The Guide is just a product of the MDBA, which is a product of the Water Act, which in turn is a product of the (hastily produced) 2007 National Plan for Water Security. Errors and false assumptions from the 2007 press release are progressively compounding and accumulating. This series of errors, assumptions and simplifications makes it quite unlikely, in my view, that the Commonwealth can 'fix the MDB' just by following the current path.

In the 2010 Productivity Commission report on recovering water in the MDB, I concluded: Australians generally want to see an environmentally sustainable Murray Darling system (including the wetlands and riparian lands as well as the rivers per se) supporting viable, sustainable, world-class agriculture and viable dynamic communities that are good places to live and raise a family. 
I believe that is still true.

But Australia is now three years into implementation of the 10-point TurnbullRudd 'strategy to fix the $\mathrm{MDB}^{\prime}$ in 10 years for $\$ 10$ billion, but with little confidence that it is going to deliver that outcome. Certainly, the $\$ 10$ or $\$ 13$ billion allocated-probably more - will all be spent over the decade of the 'strategy'. The Commonwealth will own some thousands of gigalitres of water entitlements. But it is still debatable whether the MBD ecosystems, including World Heritage Areas, Ramsar-listed wetlands, national parks and all the small unnamed wetlands, will be in much better condition than they were last year or 10,20 or 50 years ago. Even if individual elements of the landscape are improved, improving the health of the whole connected landscape must include agriculture. And the social and economic impacts on industries and communities in the Basin will be non-trivial, even though most will probably manage to adapt and survive, and some will prosper.

Campbell (2010), Ison (2007) and Myers (2010) have also commented that the problem has been constructed in an unhelpful way: as a technical issue, in which a small number of scientists will work out the 'right' answer, announce what the rest of society has to do then all interested parties will do as instructed. This is very deterministic and authoritarian - akin to NASA planning a lunar landing. Campbell, Ison and I have argued elsewhere, at various times, for a bottom-up adaptive strategy as a more effective path for dealing with water resources as a wicked problem. ${ }^{1}$

Resolving and unscrambling the legacy of diverse and inappropriate MDB arrangements are not things a 'plan' can do. Although the National Water Initiative (NWI) and the Water Act are national in a broad sense, Australia still cannot agree on a plan because the policy has not been debated. In effect, we are having the policy debate now, within the plan. Working out the policy consensus is not an appropriate task for an 'independent authority' to do.

A real policy-preceding the technical planning-would have diagnosed precisely what the problems are in the Basin, ensured a feasibility study and thorough analysis of all major outlays of public money, and then directed the available resources at ensuring sustainable use of the Basin, a sound economy, and a viable rural society not dependent on subsidies.

It is not too late to use all of the high-quality science that has been done-in a different way. Governments could start engaging seriously with people at local

1 'Wicked problems require thinking that is capable of grasping the big picture, including the interrelationships among the full range of causal factors underlying them. They often require broader, more collaborative and innovative approaches. This may result in the occasional failure or need for policy change or adjustment. They go beyond the capacity of any one organisation to understand and respond to, and there is often disagreement about the causes of the problems and the best way to tackle them.' 
and regional scales who know the details of how their ecosystems, agricultural systems and social systems interact. Without the commitment, energy and knowledge of these people, any externally imposed plan is unlikely to work. Connectedness across the landscape is crucial, not isolating everything into components - this wetland, that clump of trees, that stretch of riverbank, this species of frog - and agriculture is crucial to that connectedness. Environmental, social and economic dimensions must be integrated, instead of treating them as stand-alone silos. Landholders and catchment management authorities (CMAs) do this all the time (Robins and Dovers 2007), but governments consistently find it very difficult to operate any way other than in departmental silos (Productivity Commission 1999).

Critiques of the MDBA's Guide to the proposed Basin Plan abound. Paul Kelly (editor-at-large of The Australian), economist Henry Ergas and Andrew Campbell (the former head of Land \& Water Australia and one of the founders of Landcare) are among those who have written from the author's own perspective, and they each criticise different aspects of the current proposals. Such specific criticisms can be pieced together to seriously question the whole undertaking. Most importantly, the aim of this chapter is to suggest how the strategy could be redeemed.

\section{Four Judgments about the Existing MDB Strategy}

The Commonwealth's Murray-Darling Basin strategy to reverse environmental deterioration in the Basin was not well designed. If the problems in the Basin are to be dealt with effectively, cost effectively and equitably, we need a wellthought-out policy and the current strategy will need to be overhauled and extended.

Having presided over a Productivity Commission inquiry into the design and implementation of the strategy, and observing for the subsequent year, I have reached four conclusions.

1. Legislatively, in the form of the Water Acts 2007 and 2008, the 'strategy' is poorly designed.

2. Administratively, the 'strategy' has been set up on an ill-conceived basis with an inappropriate institutional structure.

3. Financially and economically, the 'strategy' could prove wasteful.

4. Underlying all of these deficiencies, the plan is fundamentally confused about causes and effects, and about means and ends. The problem is seen as a technical one to be solved by experts, rather than a social learning, adaptive process - an inclusive, long-term national conversation. 
I do not intend to discuss the politics, except to restate a few well-known facts: a $\$ 10$ billion policy commitment was announced before the 2007 election. Noone has ever explained where the figure of $\$ 10$ billion came from, or why 60 per cent of the $\$ 10$ billion was allocated to subsidising irrigation infrastructure. To my knowledge, no-one has even claimed that a detailed feasibility or benefitcost analysis exists, let alone has tabled one. Parliament passed the bill in 2007 unanimously in both houses without dissent.

During the 2007 election campaign, Kevin Rudd committed Labor to an extra $\$ 3$ billion for the same policy. Parliament passed the renewed bill under the new Labor government in 2008-again unanimously, in both houses, without dissent.

If anyone had asked in the Commonwealth Parliament in 2007-08 'Who wants to save the Murray-Darling Basin', all hands would have risen. But if the question was 'Does anyone understand the nature of the problems facing the $M D B$, how we got into this mess, the options for getting out of the mess, how long that will take, how much it will cost, and whose cooperation do we need to succeed' then I suspect no hand would have been raised. But no-one will ever know, because that question was not asked until now. Our purpose here is not to discuss politics, but rather to concentrate on the science, economics, and governance.

\section{Why do I assert that the legislation itself is poorly designed?}

Legislatively, the strategy has three flaws, in my view.

a) At its heart, the Water Act requires that key environmental assets and processes must not be compromised. Lawyers might argue forever about how to define 'key' and what changes, if any, amount to being 'compromised'. The estimated number of key environmental assets ranges from the 16 internationally listed wetlands, to an MDBA list of more than 33000 'significant wetlands' (including some unnamed dry watercourses) based on the International Union for Conservation of Nature (IUCN) list of rare and endangered species. The MDBA Guide refers to 2442 sites, but then focuses on 18 Hydrological Indicator Sites (HIS). If the Gwydir Wetland, for example, is a key environmental asset (and most people agree it is), how much of it must be 'not compromised'-200 000 ha, 120000 ha or just the small area (about 862 ha) that is Ramsar listed?

b) On most readings, the legislation deliberately and explicitly prevents the $M D B A$ from taking social or economic costs into account in estimating the environmental water requirements and setting the sustainable diversion limits (SDLs) for each river. The legislation mandates reduction in extractive use of water to whatever level is required to protect all environmental values (apparently without taking social or economic costs into account). The Water 
Minister, Tony Bourke, obtained a new 'legal opinion' to the effect that the Water Act permits social and economic issues to be taken into account in setting SDLs. Either way, it is unavoidable that there will be collateral costs associated with returning more water to the environment, and these costs are likely to impact on the agricultural economy of the MDB. They are likely to generate some political backlash against any government that implements an environmental plan regardless of social and economic disruption. A better piece of legislation might have carefully included such considerations.

c) Economists recognise that the quantity of water demanded by any irrigator depends on its price. But in contrast, the legislation sees the quantity of water demanded for the environment as totally independent of price-whether water has a market value of $\$ 1$ or $\$ 1000$ per megalitre, a 'key environmental asset' must have ' $\mathrm{X}$ ' ML if scientists agree that it needs X ML/year (on average) to ensure that its ecological integrity is not compromised. Many believe that the environmental benefits will be very great and/or that the economic and social costs and disruptions will be small and manageable. That might be true. It is, however, inescapable that trade-offs must be made. No process has been created to explicitly enable Australian society to have that national conversation and make those judgments.

This is a political debate about the differing values and priorities within Australian society so it must ultimately be a social consensus; environmental science, hydrology and economics can and should inform the political decision, but reciting facts cannot make such trade-offs. Any organisation that is required to make recommendations based on the benefits of restoring more water to the environment (but without considering the social and economic costs and benefits) would probably generate just the sort of acrimony now evident.

\section{So what is wrong with the way the strategy is being administered?}

The States' repeated failure to deliver a viable water policy over many years, and to reduce over-allocations to irrigation (as they had promised in 1994 and again in the 2004 National Water Initiative), was seen as confirmation that the Commonwealth Government had to impose a top-down initiative.

But designing the strategy as a top-down Commonwealth initiative was unhelpful. Local and community groups were omitted in the way the strategy was conceived. The whole Landcare network was excluded from the planning and design processes, as Andrew Campbell has pointed out. The CMAs were also excluded from the design and content of the strategy. The only reference to CMAs in Volume I of the Guide is on pages 194-5:

All basin states have existing mechanisms for integrating natural resource management at the regional level-for example through the 
implementation of regional NRM [natural-resource management] plans. To the extent that these regional plans relate to the management of water resources, it will be important that they are consistent with the directions and arrangements proposed under the Basin Plan.

But by ignoring such groups, the strategy fails to draw upon their data, experience and local environmental and agricultural knowledge. To substitute for such inputs has been extremely costly in time, effort and compensation for errors. Without these contributions, the strategy is virtually guaranteed to be, at the very least, highly contentious and inefficient.

But leaving these groups out also means that they have little commitment to the strategy. Without their commitment, the strategy will lack the necessary cooperation at the grassroots level. This is evident now-an enormous amount of goodwill and social capital have been destroyed by trying to impose a plan developed in isolation by experts, regardless of how technically excellent that plan is (or appears to be now).

\section{Is the strategy likely to be economically and financially sound?}

The strategy as currently designed has the potential to be inefficient. It will be many years before taxpayers know whether they have received value for money for the 10-year, $\$ 10$ billion 10-point strategy. It would be reassuring to have some early confirmation that it is likely to generate significant net benefits. The Governor of the Reserve Bank said in November 2010 (replying to a question about the National Broadband Network, or NBNCo) that all major public investments should be subject to feasibility studies and benefit-cost analysesbefore implementation.

The Federal Government has purchased about 1000 GL of water entitlements (on paper), but it still is not clear what the Commonwealth Environmental Water Holder (CEWH) will do with this asset. Achieving the desired environmental benefits will depend on how the CEWH uses the endowment of water, not just on the size of the endowment. For example, it now seems that, in specific places, it will be impossible to deliver the sheer volumes of water that would be needed to create over-bank flows (required to deliver the intended amounts of environmental watering of a wetland) because of hydrological constraints and the amount of flooding that would be imposed on third parties. So, if it will be necessary to use engineering works and measures that can achieve the desired results with much less water (as is being discussed for Hattah Lakes and Chowilla), the SDL might not need to be as restrictive. Using water efficiently is important, whether watering a crop or a wetland.

Second, the feasibility studies have yet to result in engineering initiatives that have made an appreciable impact on the problem. Almost $\$ 6$ billion was 
allocated over 10 years for infrastructure projects. As far as I can ascertain, none of the major infrastructure projects has yet passed even the most basic cost/ benefit analysis.

The Australian National Audit Office (ANAO 2010), the Productivity Commission and independent economist Henry Ergas concluded that the infrastructure projects could be far more expensive per megalitre of water saved than buybacks of similar water. The taxpayer could end up paying up to $\$ 10000 / \mathrm{ML}$ to obtain water rights with a market value of about $\$ 2000 /$ ML. Australians might get better value by spending that money on water buybacks. But making this level of expenditure on buybacks across the Basin in a short time might cause the unit prices (and the social and economic consequences) to rise.

In fact, it might not be necessary to spend that $\$ 6$ billion on either subsidising infrastructure or buying back water entitlements in the MDB. Perhaps a pause is possible (given the flooding) until we are confident about (or agree on) how much water is needed, when, where and how to achieve MDB environmental sustainability. It is far from clear that the best and smartest way to assist irrigators or rural communities is to offer them $\$ 6$ billion of taxpayers' money on the condition that they may spend it only on water-engineering works. Governments could actively engage with all the people concerned (not just irrigators and conservationists) and seek their vision and advice on what would give them better social, environmental and economic outcomes. It seems arrogant and presumptuous to specify in advance (without even asking) that the money is only for water engineering.

\section{Finally, why do I believe the strategy is conceptually confused?}

Conceptually, the strategy is based on this perception of 'the problem': rivers, wetlands and riparian systems in the MDB have been under severe stress; the cause is excessive extraction of water from the rivers for irrigation. If the extraction of water from rivers for irrigation is reduced to SDLs, and the water so saved is reassigned for environmental purposes then the Basin will be restored to ecosystem health - a sustainable, working river system.

This perception seems self-evident to many, but it is simplistic. It is true that there has been a decline in the environmental quality of the MDB over several decades and that this decline has coincided with a continuous increase in the extraction of water for irrigation in the MDB (until the recent decade of drought). The strategy is based on this simple perception of causality. Not only is this simple notion pervasive that 'all the environment needs is more water' but there is a corollary: 'the more water added, the better the environmental outcomes will be.' 


\section{Environmental \\ health/quality

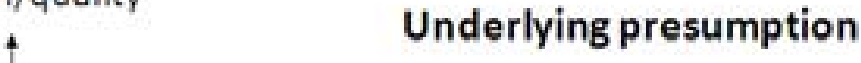

$\%$ of annual average flow extracted

Figure 24.1 Water extraction versus environmental outcomes

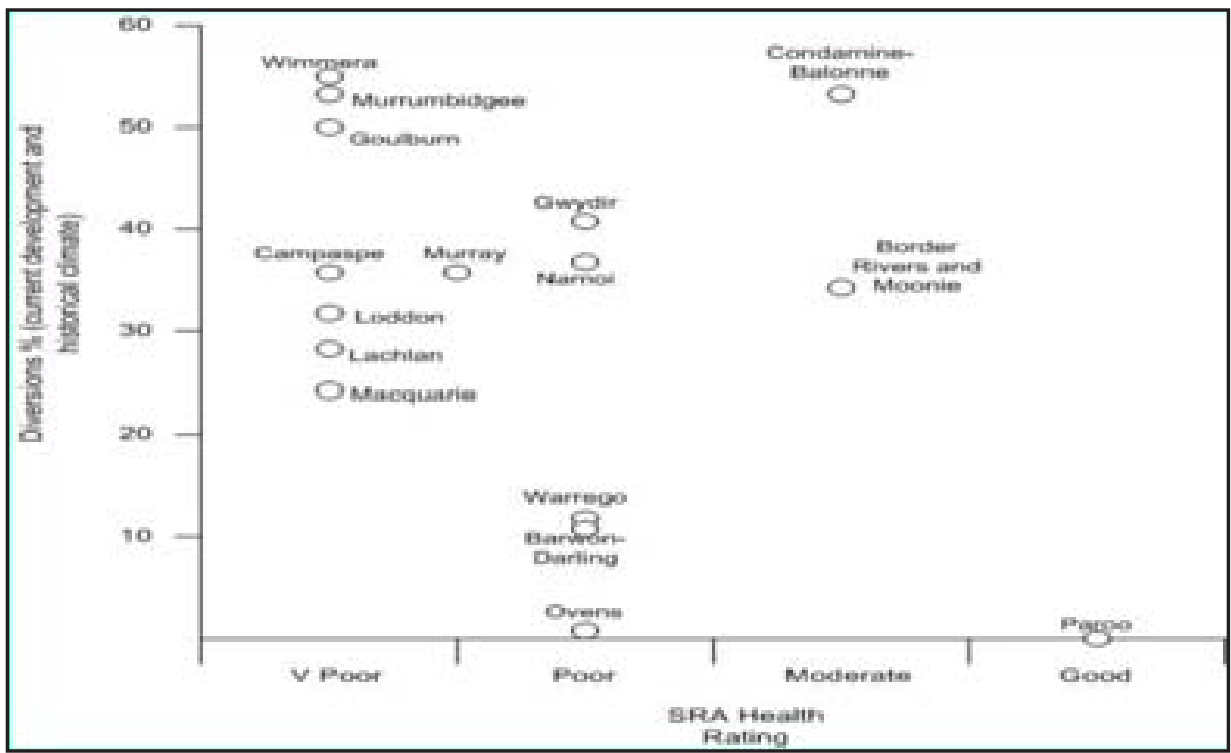

Figure 24.2 Where is the correlation?

While reducing extraction for irrigation might be necessary in many (but not all) of the rivers in the Basin, it is unlikely to be sufficient. The problems are more complex than that. Excessive extraction of water by irrigators is not the sole (and might not even be the greatest) threat to ecosystem health and sustainability in the MDB. 


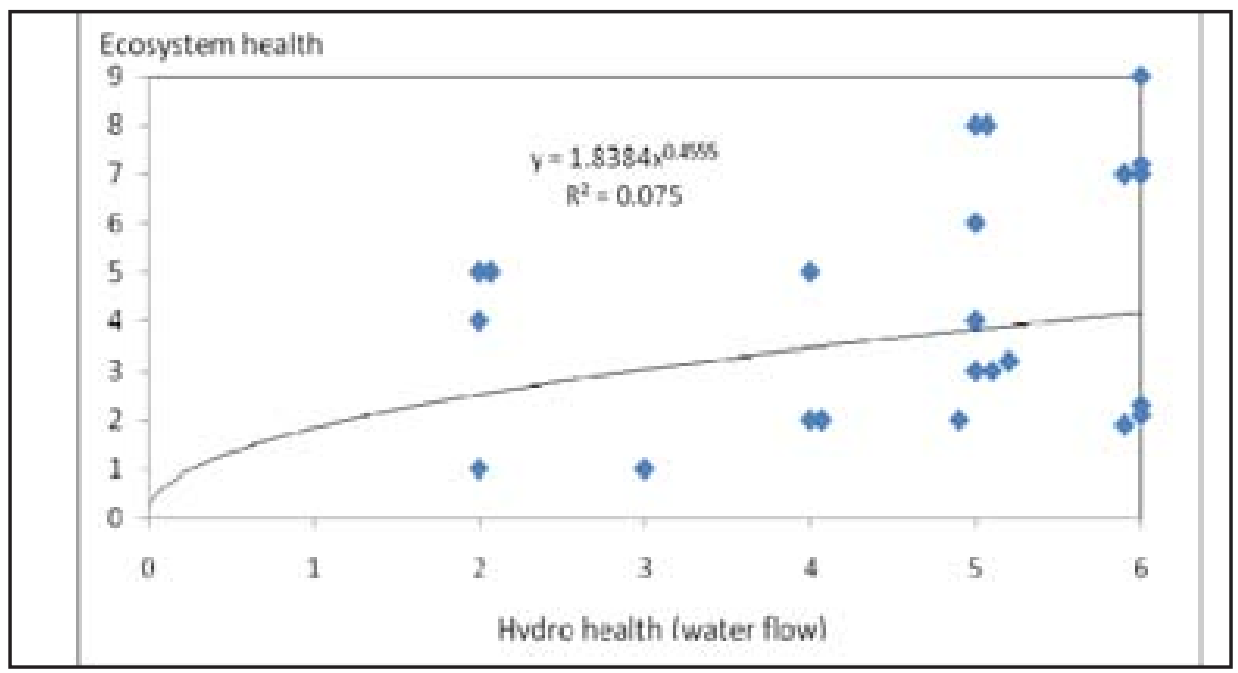

\section{Figure 24.3 Ecosystem health}

Note: The rating of 6 for hydrological health is the highest and 0 is the lowest. The rating of 9 for ecosystem health is the highest and 0 is the lowest. The ratings are altered slightly to ensure data for each river are visible. This will alter the relationship but only very slightly.

Source: MDBA (2010: Tables 2.2 and 2.3).

The highly variable outcomes for the ecosystem health of rivers or reaches that are rated the same in terms of flow conditions in the figure above suggest the need for caution. River flows seem a poor indicator of ecosystem health in highly regulated and so highly altered river systems. Unfortunately, the Guide seems to make the obvious (but possibly misleading) assumption that all that is needed for ecosystem health is to 'just add water, and the more water you add, the better it will be'.

At least four factors other than the quantity of water extracted from the rivers have contributed to environmental decline in the MDB.

1. The seasonal timing of water flows might be a more important contributor to environmental decline in the southern connected MDB than the actual quantity of flows.

2. Land-use patterns that intercept water before it ever reaches the rivers have contributed to the situation.

3. Natural-resource management issues have contributed to the problem in ways that have little to do with extraction of water from the rivers for irrigation.

4. It could be the variation in watering that matters - the timing, depth, duration, and frequency of flooding in wetlands, and the variation in river heights for in-stream and riparian biodiversity - not just the average flow per year, in the 'land of droughts and flooding rains'. 
So getting the average flow per year right is an important first step but the results depend on how the water is applied. That will not be known until the Environmental Watering Plan is finalised, and detailed on-the-ground implementation practices have been agreed on. This crucial part of the whole exercise has barely been discussed yet.

First is the matter of the timing of water flows compared with the quantity of water extracted from the rivers. Most non-specialists do not understand that the timing of water flows in the southern Basin is the major contributor to environmental decline, because water flows in the southern Basin have been re-engineered to reflect the seasonal requirements of irrigated agriculture downstream. In the headwaters of the Murray River, winter rains and snow are stored in dams and then released during the summer when needed for agriculture. This reengineering has been a significant contributor to environmental decline in the southern MDB, because the flora and fauna of the MDB had evolved to flourish in rhythm with the natural seasonal flows, which have now been inverted. As the MBDA (2010:610) states:

The ecological values of the Barmah Millewa forests have been threatened by several factors, but the main impact has been through river regulation, particularly through a decrease in medium-sized spring floods and an increase in small summer floods (MDBC 2006). Similarly GHD (2009) report that river regulation has been implicated in the steady decline of ecosystem health in the NSW Central Murray State Forests over the past 75 years - inappropriate flood regimes have been the main adverse impact on the ecological character of the site. [Emphasis added]

Second, land-use patterns that intercept water before it reaches the rivers are a factor in environmental decline in the MDB - in both the northern and the southern Basin. Farm dams are filled by intercepting rainwater that would have flowed into rivers. Overland flows are captured in southern Queensland and northern New South Wales. 'Stock and domestic' (S\&D) extractions in most of the Basin are not metered, or charged for. So as water has become scarcer, the incentive for riparian users to take as much free water as possible under the S\&D provisions becomes stronger. Plantation forestry in the upper catchments is also intercepting significant quantities of water before it ever reaches the rivers. The Guide recognises this - the MDBA has attempted to include 'interceptions' in its technical calculations - but the focus remains on reclaiming water for the environment from those who extract it from the rivers for irrigation. A problem for the MDBA (and the whole Commonwealth strategy) is that it has very limited powers under the Water Act to control interception and land use; it remains up to the States. Hopefully, the MDBA will require the States to address this between 2014 and 2019, to gain approval of their next State plans. 
Third, natural-resource management problems are a factor in environmental decline in the MDB - quite independently of the extraction of water by whatever means. Failure to take this factor into account has often meant that environmental problems have been attributed to the extraction of water for irrigation, when they might be due to other problems altogether. Many of the rivers assessed as having poor or very poor environmental health are subject to little extraction for irrigation, but are infested with feral animals, such as European carp or trout - as in the Ovens River in the figures above. Feral animals have also caused widespread damage in wetlands - for example, pigs and goats in the Macquarie Marshes. The greatest threat to the three Hydrological Indicator Sites in the Lower Lachlan River (such as the Booligal Wetlands) could be salinity, not lack of river flows. The SDL 3000 scenario in the Guide proposes to reduce irrigation extraction in the Lachlan by $44 \mathrm{GL}$, from current diversion levels of 302 GL to $258 \mathrm{GL}$ - that is, from 17 per cent of estimated long-term average flow to 14.7 per cent; and it would increase the environmental flow by the same amount that is, from 65 per cent to 67 per cent of long-term average flows. The extra 2 per cent is unlikely to 'save the wetlands' if nothing is done about the salinity threat.

A strategy that overlooks these other factors is incomplete. In fact, such a strategy will simply not be able to reverse the environmental decline in the MDB if it is not actually targeting all of the real causes of the decline. Some hope that the strategy will reverse enough of the environmental decline to make a significant impact. Perhaps, but no systematic and systemic studies that quantify the different impacts of the various causal factors underpin the current strategy. Indeed, the current strategy could actually exacerbate the environmental decline in certain parts of the MDB; by increasing water flows in some rivers, it could cause further proliferation of pests, or erosion, or salinity, which are the actual problems. In fact, for at least half of the 18 HIS that the MDBA focuses on, lack of flow volume is not the only or major threat. There is no available assessment yet of whether lack of flow is the greatest threat to the 2442 wetlands the MDBA has identified as the 'key' sites that may not be 'compromised'. Hopefully, it has not simply been assumed.

All these quibbles about the MDBA's plans could be just reactionary hype by rent seekers and lobbyists, as some say, including Henry Ergas. Proponents of the current strategy could argue that it is not intended to be 'cost effective'. But proponents should be able to argue convincingly that the strategy will be effective, and that perverse outcomes can be avoided. 


\section{Conclusions}

This chapter does not criticise the MDBA for its recent Guide; it was doing precisely what it was instructed to do by the Water Act. It is not an 'attack' on environmental scientists or conservation groups who want to see healthier ecosystems in the MDB; I share that goal. It does not 'attack' irrigators or rural interests concerned about their future (even if claims of impending catastrophe are exaggerated).

The central tenet is that this whole 'Save the $M D B^{\prime}$ ' strategy was based on a glib assumption that reducing irrigators' extractions from rivers in the MDB was necessary and sufficient to achieve a healthy, sustainable MDB. It certainly is necessary (but not equally in every valley) but it is certainly not sufficient.

If Australian governments and communities are serious about achieving an environmentally, economically and socially sustainable MDB (and I believe we all should be) then we could be wasting our collective time, effort and money on this ill-conceived strategy. I believe that the goal is quite achievable, and could even cost less than $\$ 10$ billion. But it would have to be implemented in a much smarter way, particularly by working very closely with the people on the ground who understand the complexities of the system and know what is feasible and necessary. This would probably include the design of ecosystemservice institutions capable of delivering environmental benefits as well as livelihood outcomes.

It is not too late to improve the Turnbull/Howard/Rudd/Wong strategy for the MDB to ensure it will indeed address all the differentiated, complex problems in different parts of the Basin. I argue that the key to achieve this is to start with the knowledge and energy of the people on the ground, engaging them in a serious, continuing exploration of what is feasible, workable and acceptable. This is not to suggest every valley or CMA may just do whatever it wishes. Rather governments should agree on a broad national framework within which the local and regional communities may propose workable solutions, supported by the best scientific advice they can get, from all sources.

\section{Bibliography}

Australian National Audit Office (ANAO) 2010, Performance audit: administration of the Water Smart Australia program, Auditor-General Audit Report No. 21 2009-10, Australian National Audit Office, Barton, ACT, <http://www.anao. gov.au/uploads/documents/2009-10_Audit_Report_21.pdf $>$ 
Australian Public Service Commission 2007, Tackling Wicked Problems: A public policy perspective, Australian Public Service Commission, Canberra, <http:// www.apsc.gov.au/publications07/wickedproblems.pdf>

Campbell, A. 2010, 'Rethinking the basin plan', Crikey, 16 November 2010, <http://Blogs.crikey.com.au/rooted/2010/11/16/Murray murmurings>

Ergas, H. 2010, 'Water plan will cost a tsunami', The Australian, 12 November 2010, p. 16.

Ison, R. 2007, 'New plan, same old thinking', New Matilda, 7 February 2007, $<$ www.newmatilda.com $>$

Kelly, P. 2010, 'Mighty river of trouble heading Gillard's way', Editorial, The Australian, 13 October 2010.

Murray-Darling Basin Authority (MDBA) 2010, Guide to the proposed Basin Plan.Volume 1: Overview, Murray-Darling Basin Authority, Canberra.

Myers, P. 2010, 'War over water will produce no winners', Sydney Morning Herald, 4 December 2010.

Productivity Commission 1999, Implementation of ESD by Commonwealth Departments and Agencies, Productivity Commission, Canberra.

Productivity Commission 2010, Market Mechanisms for Recovery of Water in the Murray Darling Basin, Productivity Commission, Canberra.

Robins, L. and Dovers, S. 2007, 'Community-based NRM boards of management: are they up to the task?', Australasian Journal of Environmental Management, vol. 14, no. 2, pp. 111-22. 